\title{
Main logistics digitalization features for business
}

\author{
Elena Korchagina ${ }^{1}$, Olga Kalinina ${ }^{1,{ }^{*}, \text { Anna } \text { Burova }^{2} \text {, and Natalya Ostrovskaya }}{ }^{2}$ \\ ${ }^{1}$ Peter the Great St. Petersburg Polytechnic University, 195251, Polytechnicheskaya, 29, \\ St. Petersburg, Russian Federation \\ ${ }^{2}$ Financial University under the Government of the Russian Federation (Moscow) St. Petersburg \\ branch, 197198, Syezhinskaya Str., 15-17, St. Petersburg, Russian Federation
}

\begin{abstract}
The modern foreign and domestic studies consider the digital transformation of the economy mostly as a combination of effects arising under the influence of a number of implemented digital innovations, which result in the emergence of new economic structures, new business practices, as well as new values and beliefs in the business environment. The article is devoted to the research of logistics networks development features in the context of globalization and digitalization of the economy. Issues of increasing the efficiency of the functioning of logistics networks using digital technologies through the creation of information logistics platforms also considered. As the scientific novelty of the study, it should be noted the highlighted advantages of digitalization of logistics platforms. The digital economy, in which modern logistics networks operate, is characterized by the following main features the global nature, the use of network principles for coordinating society and markets, operations with intangible benefits: information and relationships, ideas. Modern management of international logistics systems is based on the integration of digital control in the system of automatic regulation and control of the road situation and the transport situation. Thus, within the framework of the platform economy, there is a complete transformation of the existing business models. The authors prove that the features of logistics digitalization cause a significant impact on the process of logistics networks development with the necessary theoretical and methodological support for the design process of international trading.
\end{abstract}

\section{Introduction}

Digital economy being the basis of the information economy, can be characterized as a continued in the new quality and disruptive after an unprecedented technological breakthrough in the fourth industrial revolution, which is characterized by nonlinear

\footnotetext{
* Corresponding author: olgakalinina@bk.ru
} 
(exponential) rate of diffusion of innovation, depth and scale of penetration of digital technologies, impact of digital complexes and systems. The use of various digital systems and complexes changes a lot in the motivation of management decisions and the way of economic thinking, thus changing not only the productivity of economic entities, but also their economic behavior, transforming the principles of organization and functioning of both individual companies and the economic mechanism as a whole. Currently, numerous of business entities are on the verge of implementing digital transformation or digitalization or are already implementing it.

The term "digitalization" does not currently have an unambiguous interpretation, however, the very phenomenon of digitalization or digital transformation exists, and the corresponding has been launched in many companies. As a rule, each company in its own way interprets the essence of digitalization and the content of activities for the digital transformation of a business. As a result, actions taken by various companies aimed at digital transformation can often actually be far from the desired result and make it impossible to achieve the digitalization of economic activity.

In reality, the digital transformation of a business is a broader phenomenon than the digitalization of a single manufactured product, service, or any of the company's operations. This also applies to the various business processes carried out in the company.

The term "transformation" in the context of organizational change management is used to describe the degree of strategic change being implemented across the company. Transformation as an organizational change is a change in the enterprise at a fundamental level. In other words, upon transformation, an enterprise reinvents itself, namely:

- the context in which the company operates changes (the way the company works and the key factors for success);

- changes in the company's relations with key contact groups: customers and customers, employees, contractors and suppliers;

- business processes at the enterprise are changing;

- the products manufactured by the enterprise or the services provided by the enterprise are changed.

Thus, the result of organizational transformation is a conscious and sustainable change in the factors and level of effectiveness of the existing business. Business transformation can lead to the formation of new value propositions, the creation of new ways of interacting with existing and potential customers [1].

The term "digital" refers to the collection, storage, processing, provision and use of information in electronic form using information technology. In modern conditions, digital technologies and the process of their development have a significant impact on the economic environment. This is due to the fact that digital technologies are a tool for creating various cross-functional, modular and distributive business processes, thus increasing business flexibility and adaptability to the environment and its changes, as well as allowing enterprises in modern conditions to create ecosystems that are self-organized, self-adjusting systems of independent enterprises engaged in joint value creation [2].

K. Matt considers the digitalization of business as the use of modern digital technologies in the activities of the enterprise, being aimed at changing the company's key business operations, business processes, existing organizational structures and existing management concepts, products produced by the company. The advantages of digital transformation, in his opinion, are based on increasing the productivity of the enterprise and its sales, as well as on the emergence and application of innovations in creating value in the process of interaction with customers [3].

$\mathrm{S}$. Adams describes the digital transformation of a business as changing an existing enterprise in order to effectively provide existing and potential consumers with new or improved manufactured products, services, or their complex. A key factor in implementing 
a new offer of products and services or improving existing ones is the use of modern information technologies in the company's activities [4]. So, businesses are trying to create new business models that are optimal for the current environment, change their experience of working with consumers, or transform their working models by implementing digital transformation.

In most modern foreign and domestic studies, the digital transformation of the economy is understood as a combination of effects arising under the influence of a number of implemented digital innovations, which result in the emergence of new economic structures, new business practices, as well as new values and beliefs in the business environment [5-12]. These beliefs and values supported by new structures and practices lead to a change, replacement or addition of previously existing principles and methods of economic activity on the scale of individual organizations, ecosystems of organizations and even industries [3].

Gartner analyst Hung Lehong, whose work is to identify elements of digital transformation in the activities of modern organizations, argues that the goal of digital transformation of most companies is to generate new revenue streams through the creation of new products, new services or the formation of new business models [6].

The digital transformation of modern organizations is characterized by the transition to a new level of organization of production and management of value chains and management of the entire product life cycle through digital technologies. The smart factory is one of the key aspects of this new industrial revolution [3]. Basis of the digital factory concept is the digitalization of the product development process, the use of flexible production and logistics structures, intelligent solutions in the supply chain, and the integration of these processes [13-14].

\section{Materials and methods}

The process of digitalization of an enterprise may include the creation of digital business units in the structure of the enterprise, new business models based on digitalization may lead companies to create additional branch structures in related markets, as well as in new industries. General Electric's Digital Twin concept involves creating a digital double of a new product, modeling it in a virtual digital environment, testing a variety of loads, and predicting a list of possible outcomes. The company intends to sell to users digital twins of locomotive engines and jet turbines as software [7]. Thus, General Electric is launching a digital transformation of its own business, and in the future-the entire engineering industry, which will significantly change with the ubiquity of the concept of Digital Twin.

Gartner predicts that these technological mega-trends will have a strong impact on the progressive development of business and changing market conditions of technology in the next 5-10 years. According to Gartner, companies are trying to implement the above technologies in their business, and in the near future. This will lead to a complete digital transformation of the economic activities of enterprises that have implemented these technologies and will contribute to their adaptation in a rapidly changing digital environment [8].

To ensure the sustainable development of their business over the next 5-10 years, as well as to objectively identify and effectively predict opportunities and threats, today companies need to assess high-level trends in the development of digital technologies, as well as calculate their potential impact on the economic environment and its transformation under the influence of certain new technologies.

So, it is assumed that within $2-5$ years in the activities of companies will be massively introduced artificial intelligence. This technological mega-trend includes such separate technologies as machine learning of information systems, deep learning of information 
systems, creation of Autonomous robots, creation of conversational artificial intelligence (chat bots), interaction in natural language, as well as ontological enterprise management. Artificial intelligence will solve such problems of enterprises as adaptation to modern environmental conditions (which is unstable, largely uncertain, extremely ambiguous and complex), reliable forecasting of future problem and risk situations, operational interaction with consumers, as well as fundamental changes in the quality of the product and service [5].

Immersive technologies are technologies that are close to a person, they penetrate into human activity and are capable of modulating and transforming this activity. This technological mega trend includes such separate technologies as augmented and virtual reality, the use of adaptive interfaces for users with different capabilities and needs, 4D and $3 \mathrm{D}$ printing. It is expected that immersive technologies will be actively implemented in production and economic activities over the next 2-5 years. As a result, the direct connection of digital technologies with the consumer, a significant expansion of the boundaries of business, the development of the ability to modulate human behavior, direct interaction of companies with the thinking of the user-consumer will give economic entities the opportunity to operate most effectively within the three-component interaction: environment-business-man [9].Immersive technologies are technologies that are close to a person, they penetrate into human activity and are capable of modulating and transforming this activity. This technological mega-trend includes such separate technologies as augmented and virtual reality, the use of adaptive interfaces for users with different capabilities and needs, 4D and 3D printing. It is expected that immersive technologies will be actively implemented in production and economic activities over the next 2-5 years. As a result, the direct connection of digital technologies with the consumer, a significant expansion of the boundaries of business, the development of the ability to modulate human behavior, direct interaction of companies with the thinking of the user-consumer will give economic entities the opportunity to operate most effectively within the three-component interaction: environment-business-man [9].

The technological mega-trend in the development of digital platforms includes the following separate technologies: $5 \mathrm{G}$ networks, the concept of using digital product counterparts (the previously mentioned example of General Electric), quantum computing, IoT platforms (otherwise called the Internet of things), PaaS platforms (enabling the service use of software platforms), blockchain technology. The development of digital platforms will lead to an increase in business openness: an increasing number of companies will make the transition from closed organizational structures that are only available to employees of the company, to the creation of multi-subject ecosystems [8]. These ecosystems will perform most of the work on the development of companies, having a significant impact on the formation of their development strategy, the processes of interaction of companies with the internal and external environment.

\section{Results}

In our opinion, the concept of a logistics network is broader than the concept of a distribution network and should cover the "three sides" of the company's logistics activities in the formation of the logistics network. The following flows can be distinguished in the logistics network (Fig. 1). The logistics system can be considered as a mechanism for managing a set of supply chains on a certain scale. Logistics system is based on the elements of the logistics infrastructure and operates in the context of the integration of participants in transport and logistics activities within the logistics system. Concept of a logistics network can be differentiated as follows. Logistics network in general terms is a 
set of interconnected and dependent on each other centers of logistics activities, forming a certain network structure, if these centers are installed.

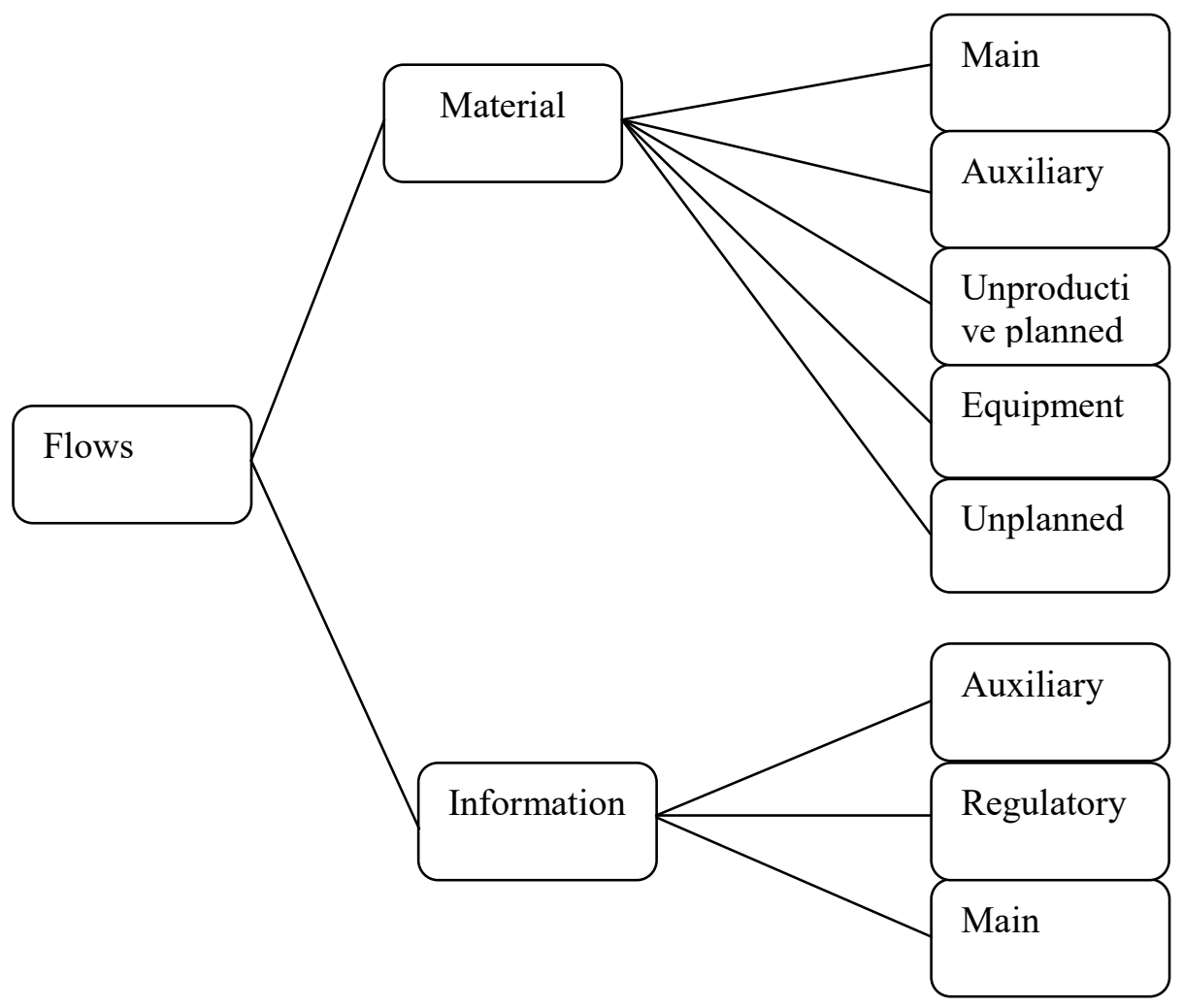

Fig. 1. Resource flows in the logistics network.

Logistics network in relation to planning is a graphical representation of the existing and potential relationships between the various centers of activity within the framework of the logistics process or a specific project? Logistics network in relation to the flow of goods is the structure of all existing distribution channels between the enterprises producing goods and distribution centers, which allows for the flow of goods, financial and information flows. As a rule, in foreign studies, the concept of a logistics network is identified within the framework of an object approach with the concept of a "supply chain" or with the concept of a "distribution network", which operates in a distribution system for commercial products. A distribution network is usually understood as a purposefully created set of channels that allow you to move inventory flows from one or more sources (producers) to distribution centers and further from distribution centers to consumers. Moreover, in the distribution network can function as one level of distribution of inventory flows, as well as several levels. Modern management of international logistics systems is based on the integration of digital control in the system of automatic regulation and control of the road situation and the transport situation. For example, in China, the total logistics management system of China Ocean Shipping Group Company recently integrated automation processes in the management and navigation of vehicles in the southern provinces of China $5 \mathrm{G}$ systems, which, thanks to Huawei, made it possible to create a unified logistics management system. 
The digital economy, in which modern logistics networks operate, is characterized by the following main features: the global nature, the use of network principles for coordinating society and markets, operations with intangible benefits: information and relationships, ideas. The technological basis of the modern digital economy is formed on the basis of the achievements of the fourth industrial revolution.

The transition of enterprises to a platform economy, where various groups of consumers, economic entities and various external processes are included in multilateral interaction, assumes that innovations in such an economy will not be individual products or services provided, but platforms that allow generating mass products and services [3]. Thus, within the framework of the platform economy, there is a complete transformation of the existing business models. Gartner's long-term forecast refers to the upcoming reform and transformation of entire operating sectors of the economy, in which the operation of the enterprise is based on the constant creation and receipt of operational data, both in physical space and in virtual space.

The term "platform" is currently interpreted by researchers in different ways. A broad interpretation of the term implies that a platform is a certain type of economic activity. In turn, a narrow interpretation of the term implies that the platform is a specific information product that operates within the digital economy. The focus on the characteristics of the platform could consider it as a tool for ensuring logistics integration. The better way is an attempt to integrate the existing concept of the platform into the structure of the value chain. However, modern domestic researchers are quite unanimous in the fact that the development of platforms in today's globalizing and digitalized economy is aimed at increasing the degree of flexibility of economic entities and adaptability to rapidly changing environmental conditions.

Among the growing variety of types of platforms, one can distinguish such a type as a logistics platform. The views of researchers on the definition of the essence of the logistics platform in various theoretical and practical studies are also quite diverse.

Thus, the logistics platform could be identified as homogeneous part of the logistics system in the supply chain centrally managed by the focus organization. So the logistics platform could be considered as a base for positioning marketing channels. From the other hand the logistics platform is a physical place where various agents of the supply chain are integrated aiming to facilitate logistics flows, acts as a strategic interface between global and regional networks in order to improve the efficiency of the supply chain. It could be proved that the logistics platform includes infrastructure for joint inter modal transportation and formation of added value.

The logistics platform is a business integrator, in which a high degree of efficiency is carried out a complex inter-organizational interaction of integrated participants in the platform for the simultaneous solution of two opposing management tasks of logistics activities-improving logistics service and reducing logistics costs, allowing take into account the interests of all participants in logistics activities.

The digital logistics platform is a special kind of organizational structure, which is based on the integration of participants in logistics activities using digital technologies and allows you to coordinate the movement of material, information and financial flows. Thus, the digital logistics platform, which is a product of digital technologies, is a format for the Association of many economically and legally independent and independent participants in the integrated supply chain of logistics activities.

\section{Discussion}

In terms of the digitalization of the economy it could be argued that the international trade undergoes digital transformation, the essence of which boils down to the use of the complex 
capabilities through information systems and information networks class IoT to stimulate foreign trade activities of the countries. This thesis regards the process of digital transformation of international trade.

Alibaba Group invests more than 15 billion US dollars in the development of the Chinese logistics network it is planned to create a transport logistics management system that will significantly reduce the delivery time of shipments around the world.

To achieve the goals of digital transformation, it is supposed to record and store all the results of routine financial and logistics operations in secure distributed registers. Storage of the results of logistics operations by participants of a foreign trade transaction is assumed until the successful closing of the transaction and, if necessary - the completion of the subsequent warranty period.

\section{Conclusions}

Thus, the digitalization of an enterprise is a global transformation that affects various aspects of the organization's business activities, from the production process to the organizational structure. The essence of digitalization of the company's activities is not to digitize any channel or a separate production operation, a separate business process, but in a comprehensive approach to the transformation of the company's activities, which covers all areas of the company's operation and all areas of economic activity.

Most enterprises, mainly industrial, measure the level of digitalization of their own economic activities using the level of automation of routine operations. However, automation of routine operations is the digitization of a specific process from the value chain. Digitalization can be seen as the integration of material and commodity flows and the optimization of the movement of these flows throughout the value chain. The basis for integrating and optimizing the flow of these flows is the sequential digitization of the data flow that moves throughout the company's value chain.

The reported study was funded by RFBR according to the research project № 20-014-00029.

\section{References}

1. D. Herzig, T. Bauernhansl, Procedia CIRP 67, 540-545 (2018).

2. A. Moeuf, S. Lamouri, R. Pellerin, S. Tamayo-Giraldo, E. Tobon-Valencia, R. Eburdy, International Journal of Production Research 58(5), 1384-1400 (2020).

3. N. Bleiman, Dividends of the digital age. http://www.rbcplus.ru/news/59ef050d7a8aa91b5266834d

4. B. Hinings, T. Gegenhuber, R. Greenwood, Information and organization 28 (1), 52-61 (2018).

5. S. Adams, Clayton Christensen On Being Wrong About Disruptive Innovation. https://www.forbes.com/sites/forbestreptalks/2016/10/03/clayton-christensenon-what-he-got-wrong-about-disruptive-innovation/\#35cd8e81391b

6. R. Burke, A. Mussomeli, S. Laaper, M. Hartigan, B. Sniderman, Deloitte Insights, 29-37 (2017).

7. Gartner identifies five new technological trends that blur the boundaries between man and machine. https://www.gartner.com/en/newsroom/pressreleases/2018-08-20-gartner-identifies-five-emerging-technology-trends-that- 
will-blur-the-lines-between-human-and-machine

8. P. Dahlström, D. Desmet, M. Singer, The seven decisions that matter in a digital transformation: A CEO's guide to reinvention. Digital McKinsey 72-78 (2017). https://www.mckinsey.com/business-functions/mckinsey-digital/ourinsights/the-seven-decisions-that-matter-in-a-digital-transformation

9. O. Scalabr, Embracing Industry 4.0 - and rediscovering growth (2016). https://www.bcg.com/ru-ru/capabilities/operations/embracing-industry-4.0rediscovering-growth.aspx

10. Top 10 Gartner forecasts for IT in 2019 and beyond. https://www.forbes.com/sites/louiscolumbus/2018/10/16/gartners-top-10predictions-for-it-in-2019-and-beyond/\#4323a373713f

11. M. Li, A. L. Porter, A. Suominen, Innovation and Emerging Technology, 8995 (2017). https://par.nsf.gov/servlets/purl/10076503

12. C. Matt, T. Hess, A. Benlian, Digital transformation strategies. Business And Information Systems Engineering 57 (5), 339-343 (2015).

13. Neutral logistics information platform (NLIP): www.nlip.org .

14. F. Pinzaru, Management in the digital economy: an introduction to the discussion Pannon Management Review. http://pmr.unipannon.hu/articles/4_2_pinzaru.pdf

15. A report from Deloitte's of research center for energy and industrial group. 2019 Deloitte and MAPI Smart Factory Study. https://www2.deloitte.com/content/dam/insights/us/articles/6276_2019Deloitte-and-MAPI-Smart-Factory-Study/DI_2019-Deloitte-and-MAPI-SmartFactory-Study.pdf

16. S. Krasnov, E. Zotova, S. Sergeev, A. Krasnov, M. Draganov, IOP Conference Series: Materials Science and Engineering 618 (1), 012069 (2019).

17. S. Lisitsa, A. Levina, A. Lepekhin, E3S Web of Conferences 110, 02061 (2019).

18. S. Vorobyov, L. Perlovsky, V. Yadykin, IOP Conference Series: Materials Science and Engineering 497, 012038, (2019).

19. O. Rasskazova, O. Kalinina, E. Zotova, MATEC Web of Conf. 170, 01058 (2018).

20. T. Fejling, E. Torosyan, O. Tsukanova, O. Kalinina, IOP Conference Series: Materials Science and Engineering 497, 012027 (2019). 